\title{
The Effect of Vitamin C Therapy Towards Malondialdehyde Plasma Content on Chronic Tonsillitis Patients With Risk of Obstructive Sleep Apnea Syndrome
}

\author{
Sutji Pratiwi Rahardjo Hiro ${ }^{1}$, Hiro Salomo Mangape ${ }^{1}$, Abdul Qadar Punagi ${ }^{1} \&$ Andi Nilawati Usman ${ }^{2,3}$ \\ ${ }^{1}$ Nose, and Throat Department, Head and Neck Surgery, Faculty of Medicine, Hasanuddin University, Makassar, \\ Indonesia \\ ${ }^{2}$ Halal Center, Hasanuddin University, Makassar, Indonesia \\ ${ }^{3}$ Public Health, Mandala Waluya College, Indonesia \\ Correspondence: Andi Nilawati Usman, Faculty of Public Health, Hasanuddin University, Makassar 90245, \\ Indonesia. Tel: 628-525-599-0153. E-mail : nilawatiandi@gmail.com
}

Received: May 26, 2018 Accepted: July 29, 2018 Online Published: August 23, 2018

doi:10.5539/gjhs.v10n9p97 URL: https://doi.org/10.5539/gjhs.v10n9p97

\begin{abstract}
Introduction: Sleep Apnea Syndrome is a syndrome with an episode of apnea or hypopnea during sleep. The objective of this study was to investigate the effect of the vitamin C therapy to plasma Malondialdehyde (MDA) level in patients with chronic tonsillitis who have a risk factor of Obstructive Sleep Apnea Syndrome (OSAS), measured pre and post-therapy.

Methods: The design of this study was a clinical trial with pre-test and post-test control group. This study was conducted in Dr. Wahidin Sudirohusodo Hospital and Hasanuddin University Teaching Hospital in Makassar and 30 subjects was enrolled (20 subjects were patients with chronic tonsillitis and OSAS, and 10 subjects were control). The measurement of plasma MDA level was obtained using ELISA method. The data were analyzed using the Mann-Whitney test and Chi-square test.

Results: The results of this study showed a decreasing level of plasma MDA in patients with chronic tonsillitis and OSAS after the vitamin $\mathrm{C}$ therapy. However, there was no significant difference between patients who had not received vitamin $\mathrm{C}$ therapy.
\end{abstract}

Conclusion: The intervention of vitamin $\mathrm{C}$ in chronic tonsillitis patients and can reduce levels of plasma MDA.

Keywords: plasma MDA level, chronic tonsillitis, obstructive sleep apnea syndrome (OSAS), vitamine C

\section{Introduction}

Sleep apnea syndrome is a syndrome with an episode of apnea or hypopnea during sleep. Apnea can be caused by central abnormalities, airway obstruction, or both. Obstructive apnea is a condition with cessation of airflow in the nose and mouth with breathing effort, whereas central apnea is a respiratory cessation that is not accompanied by breathing effort due to the absence of breath stimulation. Hypoventilation obstruction is caused by partial obstruction of air flow causing hypoventilation and hypoxia. The term hypoventilation obstruction is used to indicate the presence of hypopnea, which implies a reduction in airflow (Rosen et al., 2012; Spicuzza, Caruso, \& Di Maria, 2015; Swedish Council on Health Technology, 2007). Obstructive sleep apnea (OSA) is characterized by a period of repeated upper airway collapse that leads to a hypoxia / reoxygenation cycle causing increased oxygen species formation by oxidative stress (Patil, Schneider, Schwartz, \& Smith, 2007; Sunitha \& Aravindkumar, 2009).

Intermittent hypoxia can lead to increased oxygen-free radical formation. One of the lipid oxidation products is Malondialdehyde (MDA) which is used as biomarker on oxidative stress test. MDA is an unsaturated fatty acid oxidation product by free radicals. Increased MDA concentration indicates free radicals involvement. Oxidation reactions cause oxidative damage eventually, resulting in cell damage and death (Behn, Araneda, Llanos, Celedon, \& Gonzalez, 2007; Chantharaksri, Tonsuwonnont, Fucharoen, \& Wasi, 1992; Freudenthaler, Schreeb, Wiese, Pilz, $\&$ Gleiter, 2002).

Plasma MDA levels as a free radical biomarker was higher in patients with chronic tonsillitis who had OSAS than who had not OSAS (Asker et al., 2015; Kang, Jung, \& Kim, 2013; Tauman, Lavie, Greenfeld, \& Sivan, 2014). 
Increased levels of free radicals can be neutralized by antioxidants. The body has the ability to produce endogenous antioxidants such as gluthatione, superoxide dismutase, and catalase. However, these substances are not sufficient to neutralize excessive free radicals that are formed. Therefore, exogenous antioxidants was required, one example is vitamin C. Vitamin C is known as a potent compound to ward off free radicals. The use of vitamin $\mathrm{C}$ as one of the natural antioxidants is widely recommended in treating and detoxifying (reducing toxins) the condition. Free radical damage results in the occurrence of some diseases (Getoff, 2013; Tariq, 2007).

The provision of vitamin $\mathrm{C}$ can reduce levels of Malondialdehyde (MDA), supplementation $250 \mathrm{mg}$ vitamin $\mathrm{C}$ for 12 weeks to hemodialysis patients decreases MDA levels also prevent complications of diabetes mellitus (Abdollahzad et al., 2009; Mazloom et al., 2011). Vitamin C supplements also increase superoxide dismutase (SOD) activity, glutathione peroxidase (GPx), the levels of vitamin E, total antioxidant capacity (TAC) and a significant decrease in MDA (Karajibani, Hashemi, Montazerifar, \& Dikshit, 2010).

Based on these, we were excited to investigate the effect of Vitamin $\mathrm{C}$ therapy on the level of plasma malondialdehyde (MDA) in a patient with chronic tonsillitis with the risk of obstructive sleep apnea syndrome (OSAS) at pre-and post-therapy.

\section{Materials and Methods}

\subsection{Location and Period of Study}

This study was conducted at ENT-Head and Neck Department Dr. Wahidin Sudirohusodo Hospital, and Hasanuddin University Teaching Hospital. The study period starts from August 2017 to January 2018.

\subsection{Study Design and Variable}

This study was quasi-experimental study with pre and post-test control group design. The study variables consist of: independent variable (vitamin C), dependent variable (plasma MDA level), and intermediate variables (tonsillar hypertrophy, incomplete pharyngeal obstruction, hypoxia state and free radical increase).

\subsection{Population and Sample}

The population of the study was all patients with chronic tonsillitis who came for treatment at ENT-Head and Neck Department Dr. Wahidin Sudirohusodo Hospital and Hasanuddin University Teaching Hospital. The study was held from August 2017 to January 2018. The study sample is part of the population that meets the inclusion criteria (chronic tonsillitis, Age 15 - 40 years, disposed of and understand the assessment instructions of the Berlin questionnaire, Not taking vitamin C supplementation within the last 1 month, willing to participate in the study and give informed consent.

Ethical approve from the ethical committee of Hasanuddin University, faculty of medicine.

\subsection{Intervention}

History taking, ENT examination: otoscopy, anterior and posterior rhinoscopy, pharyngoscopy, indirect laryngoscopy. Those who meet the inclusion criteria are included as sample. The accompanying subject or family signed the informed consent. The subjects filled out a Berlin questionnaire containing the OSA symptom evaluation. The given vitamin $\mathrm{C}$ dose was $2 \times 500 \mathrm{mg} /$ patient for three weeks. Period of examination of plasma MDA level was before and after 3 weeks of therapy.

\subsection{Data Analysis Technique}

Plasma MDA level was examinated using enzyme-linked immunosorbent assay (ELISA) used BioAssay Technology Laboratory kit (the procedure of laboratory using its instruction) in in the laboratory of molecular biology of Hasanuddin University hospital.

All data was obtained, grouped in accordance with the purpose and type of data, to be further tested using Mann Whitney and Chi Square analysis. Data was processed using computerized system. Assessment of hypothesis test result is significant if $\mathrm{p}<0.05$.

\section{Results}

Study have been conducted with pre and post-test control group design to determine the effect of Vitamin C therapy to the levels of MDA in patients with chronic tonsillitis with the risk of obstructive sleep apnea syndrome (OSAS) pre and post-therapy of vitamin C. The study was conducted at the ENT-Head and Neck Department Dr.Wahidin Sudirohusodo Hospital and Hasanuddin University Teaching Hospital from August 2017 to January 2018.

During the period, patients with chronic tonsillitis who met the inclusion criteria fill out the Berlin questionnaire to 
assess the presence of OSAS risk, then were examined to measure their plasma MDA levels. The results of this study were among 30 subjects, 20 of them were patients with chronic tonsillitis, in which half was given vitamin C therapy and the rest was not, and another 10 subjects were control.

Generalized and clinical characteristics of the results of this study illustrate the variables studied in the control group, group of chronic tonsillitis with the risk of OSAS without treatment of vitamin $\mathrm{C}$ (control without treatment), and group of chronic tonsillitis with the risk of OSAS with vitamin $\mathrm{C}$ treatment, including gender, age, BMI, tonsil size, and Berlin score. The proportion of women is higher $(56.7 \%)$ than males $(43.3 \%)$. The distribution of most age in groups was 15-20 year old (40\%). The most common BMI was normoweight, as much as 26 subjects $(86.7 \%)$. The most common tonsil enlargement were T2-T2 by 13 samples (43.4\%). Berlin's highest scores are in the group with OSAS as many as 20 samples $(66.7 \%)$ (Table 1).

Table 1. Sample Characteristics

\begin{tabular}{lll}
\hline Characteristics & $\mathbf{n}$ & $\mathbf{\%}$ \\
\hline Gender & 13 & 43,3 \\
Male & 17 & 56,7 \\
Female & & \\
Age (years) & 12 & 40 \\
$15-20$ & 6 & 20 \\
$20-25$ & 6 & 20 \\
$26-30$ & 4 & 13,3 \\
$31-35$ & 2 & 6,7 \\
$36-40$ & & \\
\hline BMI & 26 & 86,7 \\
Normoweight & 4 & 13,3 \\
Overweight & & 33,3 \\
Size of Tonsils & 10 & 43,4 \\
T1-T1 & 13 & 23,3 \\
T2-T2 & 7 & 66,7 \\
T3-T3 & & 33,3 \\
\hline Berlin Score & 20 & \\
OSAS & 10 & \\
NON OSAS & & \\
\hline
\end{tabular}

The association of tonsil enlargement in the control group, control with and without treatment showed a significant association with $p<0.05$ (Table 2). The OSAS linkages in the control group, controls with and without treatment had a significant association with $\mathrm{p}<0.05$ (Table 3 ).

Table 2. Association tonsil size with intervention

\begin{tabular}{|c|c|c|c|c|}
\hline \multirow[b]{2}{*}{ Tonsil Size } & \multicolumn{3}{|c|}{ Group (\%) } & \multirow[b]{2}{*}{$\mathbf{P}$} \\
\hline & Control & $\begin{array}{ll}\text { Control without } \\
\text { Intervention }\end{array}$ & Intervention & \\
\hline T1-T1 & 100,0 & 0,0 & 0,0 & \\
\hline T2-T2 & 0,0 & 60,0 & 70,0 & $0,001^{*}$ \\
\hline T3-T3 & 0,0 & 40,0 & 30,0 & \\
\hline
\end{tabular}

*Chi-Square test. 
Table 3. Association OSAS with intervention

\begin{tabular}{lllll}
\hline \multirow{2}{*}{ Berlin Score } & \multicolumn{2}{l}{ Group $(\mathbf{\%})$} & & Intervention \\
\cline { 2 - 4 } & Control & Control without intervention & 100,0 & $0,001^{*}$ \\
\hline OSAS & 0,0 & 100,0 & 0,0 & \\
\hline
\end{tabular}

*Chi-Square Test.

Mean plasma MDA level after treatment in the control group without treatment was 9,712 $\mu$ mol/1 and in the treatment group was $7.053 \mu \mathrm{mol} / 1$. This information showed no difference in plasma MDA levels after therapy in the untreated control group and treatment group $(\mathrm{p}>0.05)$ (Table 4$)$.

Table 4. Differences in plasma mda level after administration of therapy

\begin{tabular}{llll}
\hline Group & $\mathbf{n}$ & MDA Level $(\boldsymbol{\mu m o l} / \boldsymbol{l})$ & P \\
\hline Control without intervention & 10 & 9,712 & $0,392 *$ \\
Intervention & 10 & 7,053 & \\
\hline
\end{tabular}

* Independent T-test.

The mean decrease of plasma MDA level in the group without treatment was $20,510 \mu \mathrm{mol} / 1$, and in treatment group was $-2,24 \mu \mathrm{mol} / 1$. This indicates a significant decrease in plasma MDA levels $(\mathrm{p}<0.05)$. This could be interpreted also that the use of therapy with additional vitamin $\mathrm{C}$ can lower the plasma MDA levels in the treatment group (Table 5).

Table 5. Relation of Vitamin C to Plasma MDA Decrease

\begin{tabular}{|c|c|c|c|}
\hline Group & Decreasing of $M D A$ level $(\mu \mathrm{mol} / \mathrm{l})$ & $\mathbf{n}$ & $\mathbf{p}$ \\
\hline Control without intervention & 20,510 & 10 & $0,018^{*}$ \\
\hline Intervention & $-2,24$ & 10 & \\
\hline
\end{tabular}

* Independent T-test.

\section{Discussion}

This study showed that there was a decrease in plasma MDA levels in chronic tonsillitis patients with risk of OSAS after Vitamin $\mathrm{C}$ therapy, but there was no significant difference in plasma MDA level among chronic tonsillitis patients with the risk of OSAS given Vitamin C therapy and without therapy of Vitamin C.

Based on the results of the analysis of differences in plasma MDA levels between controls, controls with and without treatment showed significant differences in plasma MDA prior to therapy between the control group and the untreated control group $(\mathrm{p}<0.05)$, and plasma MDA prior to therapy between the control group and treatment $(\mathrm{p}<0.05)$. There was no significant difference in plasma MDA after treatment between the untreated control and treatment group $(\mathrm{p}>0.05)$.

Increased plasma MDA levels in patients with chronic tonsillitis with the risk of OSAS caused by chronic hypoxic conditions that occur in chronic tonsillitis group with risk OSAS. This hypoxia condition results in increased formation of Reactive Oxygen Species (ROS) within the cell. ROS sources in hypoxic conditions are primarily derived from mitochondria and enzyme activity of NADP $(\mathrm{H})$ oxidase and xanthine oxidase. As the product of ROS oxidation, MDA will increase and provide a picture of the damage caused by body antioxidants that can not be overcome with increased oxidant substances. Longer vitamin $C$ therapy is required to get the maximum results, this study only interferes with vitamin $\mathrm{C}$ for three weeks and chronic conditions need more than three weeks to decrease MDA level significantly.

Some existing studies only intervene with vitamin $\mathrm{C}$ in subjects who are still healthy or have not experienced chronic conditions so that the results are maximized (Popovic et al., 2015). Iron deficiency (female youth) needs 
12 weeks and combined with iron supplement to decrease reactive oxygen species (Khoshfetrat et al., 2013).

Yulistiana et al (2016) found that vitamin C 1X $1000 \mathrm{mg} /$ day/person during hospitalization can reduce plasma IL-6 levels, plasma MDA, and shorten the length of hospitalization of acute exacerbation COPD, but statistically, no significant difference was found in comparison with the control group. Vitamin $\mathrm{C}$ is one of the water-soluble vitamins that have the effect, among others, as antioxidants, anti-inflammatory, and can improve the immune system. The antioxidant effects of vitamin $\mathrm{C}$ as free radical scavenging and inhibit lipid peroxidation process. With the provision of vitamin $\mathrm{C}$ in this study is expected to reduce plasma MDA levels, so as to speed up the clinical improvement.

\section{Conclusions and Recommendations}

The investigators concluded that there was a decrease in plasma MDA levels in chronic tonsillitis patients with the risk factor of OSAS after supplemental therapy of Vitamin C. There was no significant difference in plasma MDA levels between chronic tonsillitis patients who had risk of OSAS with vitamin C therapy and without therapy. We recommended that additional therapy of vitamin $\mathrm{C}$ as an antioxidant can be considered in the management of chronic tonsillitis with the risk of OSAS. Longer vitamin $\mathrm{C}$ therapy is required to get the maximum results.

\section{Competing Interests Statement}

The authors declare that there are no competing or potential conflicts of interest.

\section{References}

Abdollahzad, H., Eghtesadi, S., Nourmohammadi, I., Khadem-Ansari, M., Nejad-Gashti, H., \& Esmaillzadeh, A. (2009). Effect of vitamin C supplementation on oxidative stress and lipid profiles in hemodialysis patients. Int J Vitam Nutr Res, 79(5-6), 281-287. https://doi.org/10.1024/0300-9831.79.56.281

Asker, S., Asker, M., Sarikaya, E., Sunnetcioglu, A., Aslan, M., \& Demir, H. (2015). Oxidative stress parameters and their correlation with clinical, metabolic and polysomnographic parameters in severe obstructive sleep apnea syndrome. Int J Clin Exp Med, 8(7), 11449-11455.

Behn, C., Araneda, O. F., Llanos, A. J., Celedon, G., \& Gonzalez, G. (2007). Hypoxia-related lipid peroxidation: evidences, implications and approaches. Respir Physiol Neurobiol, 158(2-3), 143-150. https://doi.org/10.1016/j.resp.2007.06.001

Chantharaksri, U., Tonsuwonnont, W., Fucharoen, S., \& Wasi, P. (1992). Pathogenesis of hypoxemia. Southeast Asian J Trop Med Public Health, 23(Suppl 2), 32-35.

Freudenthaler, S. M., Schreeb, K. H., Wiese, A., Pilz, J., \& Gleiter, C. H. (2002). Influence of controlled hypoxia and radical scavenging agents on erythropoietin and malondialdehyde concentrations in humans. Acta Physiol Scand, 174(3), 231-235. https://doi.org/10.1046/j.1365-201x.2002.00946.x

Getoff, N. (2013). Vitamin C: electron emission, free radicals and biological versatility. In Vivo, 27(5), 565-570.

Kang, I. G., Jung, J. H., \& Kim, S. T. (2013). The effect of obstructive sleep apnea on DNA damage and oxidative stress. Clin Exp Otorhinolaryngol, 6(2), 68-72. https://doi.org/10.3342/ceo.2013.6.2.68

Karajibani, M., Hashemi, M., Montazerifar, F., \& Dikshit, M. (2010). Effect of vitamin E and C supplements on antioxidant defense system in cardiovascular disease patients in Zahedan, southeast Iran. J Nutr Sci Vitaminol (Tokyo), 56(6), 436-440. https://doi.org/10.3177/jnsv.56.436

Khoshfetrat, M. R., Mohammadi, F., Mortazavi, S., Rashidi, A., Neyestani, T., Kalantari, N., \& Esmaillzadeh, A. (2013). The effect of iron-vitamin C co-supplementation on biomarkers of oxidative stress in iron-deficient female youth. Biol Trace Elem Res, 153(1-3), 171-177. https://doi.org/10.1007/s12011-013-9695-7

Mazloom, Z., Hejazi, N., Dabbaghmanesh, M. H., Tabatabaei, H. R., Ahmadi, A., \& Ansar, H. (2011). Effect of vitamin $\mathrm{C}$ supplementation on postprandial oxidative stress and lipid profile in type 2 diabetic patients. Pak $J$ Biol Sci, 14(19), 900-904. https://doi.org/10.3923/pjbs.2011.900.904

Patil, S. P., Schneider, H., Schwartz, A. R., \& Smith, P. L. (2007). Adult obstructive sleep apnea: pathophysiology and diagnosis. Chest, 132(1), 325-337. https://doi.org/10.1378/chest.07-0040

Popovic, L. M., Mitic, N. R., Miric, D., Bisevac, B., Miric, M., \& Popovic, B. (2015). Influence of vitamin C supplementation on oxidative stress and neutrophil inflammatory response in acute and regular exercise. Oxid Med Cell Longev, 2015, 295497. https://doi.org/10.1155/2015/295497

Rosen, C. L., Auckley, D., Benca, R., Foldvary-Schaefer, N., Iber, C., Kapur, V., . . Redline, S. (2012). A multisite randomized trial of portable sleep studies and positive airway pressure autotitration versus laboratory-based 
polysomnography for the diagnosis and treatment of obstructive sleep apnea: the HomePAP study. Sleep, 35(6), 757-767. https://doi.org/10.5665/sleep.1870

Spicuzza, L., Caruso, D., \& Di Maria, G. (2015). Obstructive sleep apnoea syndrome and its management. Ther Adv Chronic Dis, 6(5), 273-285. https://doi.org/10.1177/2040622315590318

Sunitha, C., \& Aravindkumar, S. (2009). Obstructive sleep apnea: clinical and diagnostic features. Indian J Dent Res, 20(4), 487-491. https://doi.org/10.4103/0970-9290.59457

Swedish Council on Health Technology, A. (2007). SBU Systematic Reviews. In Obstructive Sleep Apnoea Syndrome: A Systematic Literature Review. Stockholm: Swedish Council on Health Technology Assessment (SBU)

Tariq, S. A. (2007). Role of ascorbic acid in scavenging free radicals and lead toxicity from biosystems. $\mathrm{Mol}$ Biotechnol, 37(1), 62-65. https://doi.org/10.1007/s12033-007-0045-x

Tauman, R., Lavie, L., Greenfeld, M., \& Sivan, Y. (2014). Oxidative stress in children with obstructive sleep apnea syndrome. J Clin Sleep Med, 10(6), 677-681. https://doi.org/10.5664/jcsm.3800

Yulistiana F, Suradi, Reviono, Sutanto YS, Raharjo AF, Makhabah DN. Effect of Vitamin C on Interleukin-6 Plasma, MDA Plasma, and Length of Hospitalization of Exacerbated COPD Patients. Jurnal Respirologi Indonesia, 36(3), 2016.

\section{Copyrights}

Copyright for this article is retained by the author(s), with first publication rights granted to the journal.

This is an open-access article distributed under the terms and conditions of the Creative Commons Attribution license (http://creativecommons.org/licenses/by/4.0/). 